\title{
Memórias históricas
}

\section{de movimentos rurais -}

\section{Juiz de Fora na passagem do século XIX ao $X X^{*}$}

\section{Elione Silva Guimarães ${ }^{* *}$}

Neste artigo, analiso um amplo leque de fontes que revelaram fragmentos dos movimentos e dos conflitos ocorridos na zona rural de Juiz de Fora (Zona da Mata mineira) ao longo de cinqüenta anos (1878-1928). As histórias que serão aqui analisadas nos dão a conhecer as conquistas e as derrotas que se forjaram nas vicissitudes da vida e nos desnudam as estratégias de sobrevivência de homens do campo à luz das demandas judiciais no jogo de poder sobre o direito à terra.

Palavras-chave: Movimentos Rurais - Demandas Judiciais - Afro-descendentes

\footnotetext{
* Artigo recebido em outubro de 2006 e aprovado para publicação em dezembro de 2006. A análise apresentada neste artigo constitui-se de uma síntese da segunda parte de minha tese de doutoramento, defendida na UFF, em 2004, e pode ser acompanhada detalhadamente em Elione Silva Guimarães, Múltiplos viveres de afrodescendentes na escravidão e no pós-emancipação: Família, trabalho, terra e conflito (Juiz de Fora - MG, 1828-1928). São Paulo, Annablume; Juiz de Fora, Funalfa Edições, 2006.

** Professora e Pesquisadora do Arquivo Histórico de Juiz de Fora/Diretoria de Administração e Recursos Humanos/Prefeitura de Juiz de Fora. E-mail: elioneguimaraes@yahoo.com.br.
} 
Historical memories of rural Movements in Juiz de Fora in the Turn of the Nineteenth century

The article analyzes a large set of historical sources which reveled fragments on movements and conflicts occurred in the rural area of Juiz de Fora (Zona da Mata mineira, Brasil) through a period of fifty years (1878-1928). The histories analysed give us the knowledge of the victories and defeats forged in the vicissitudes of life and denude the countrymen strategies of survival under the lawsuits in the play of power to have a rigth to land.

Keywords: Rural Movements - Lawsuits - Afrodescendants

Mémoires historiques des mouvements ruraux à Juiz de Fora au passage du $\mathrm{XIX}^{\text {ème }}$ au $\mathrm{XX}^{\mathrm{ème}}$ siècle

Dans cet article j'analyse un large corpus de sources qui exhibent des fragments des mouvements et des conflits ayant lieu dans la zone rurale de Juiz de Fora (Minas Gerais, Brésil) entre 1878 et 1928. Les histoires analysées ici nous montrent les conquêtes et les défaites qui se sont forgées dans les vicissitudes de la vie et nous dévoilent les stratégies de survie des paysans à la lumière des procès judiciaires dans le cadre des enjeux du pouvoir sur le droit à la terre.

Mots-clés: Mouvements Ruraux - Procès Judiciaires - Descendants Africains

\section{Movimentos rurais em Juiz de Fora Oitocentista}

Respeitável tio Manuel Balbino de Mattos,

Prezado tio e sogro, ontem às 9:45 horas da noite, fui sabedor que entraram certo numero de gado, pertencente ao Antonio Sobreira, para seus pastos sem o seu consentimento. Pois julgando eu que o senhor não tendo feito partilha com os seus filhos e nem tão pouco passado procuração a ninguém para por e dispor do que é seu, julgo isto uma afronta, um desprezo à sua pessoa que tanto tem trabalhado e lutado até hoje, e depois de velho não pode absolutamente levar esta dor moral para debaixo da terra, que dói mais do que a física. Hoje vou arrastado por tamanha afronta tomar uma satisfação e julgo ser muito séria, a que só lhe peço velar pelos seus sete netos, que são meus filhos, e não se incomode comigo, deixe-me cumprir o meu destino. Já que Deus não me deu a sua calma tenho que, de qualquer maneira, vingar-me ou morrer, visto julgar-me com o direito de homem como muitos outros. 
Amparai os meus queridos filhos. Peço a sua benção, talvez pela ultima vez. Seu sobrinho e genro que muito lhe estima.

\section{Pedro Balbino de Mattos ${ }^{1}$}

O texto que inicia esta discussão reproduz o conteúdo de uma carta que foi encontrada no bolso de uma vítima de assassinato, ocorrido na primavera de 1919, no povoado de Benfica, próspero subúrbio de Juiz de Fora (Zona da Mata de Minas Gerais). ${ }^{2} \mathrm{Na}$ manhã do dia 8 de outubro, o lugarejo foi cenário de um triplo homicídio que provocou perturbação nas pessoas que dele tomaram conhecimento. Os assassinatos de 1919 marcam um dos momentos de confronto, resultado de longos anos de tensão e que, por sua vez, se desdobraram em conflitos futuros.

A leitura da carta sugere uma história que não é incomum nestes "brasis" uma história de desmando e resistência, luta e morte em defesa do direito a um pedaço de terra. Por julgar-se "com o direito de homem como muitos outros", Pedro Balbino de Mattos, sobrinho e genro do Major e fazendeiro Manoel Balbino de Mattos e neto do ex-escravo Balbino, juntamente com o primo João, ousou tomar satisfações ao Coronel Antônio José Sobreira, fazendeiro e um dos maiores produtores de gado da região, porque este estava invadindo as terras do velho tio. Mas o Coronel entendeu que não tinha que "dar satisfações a negros", provocando uma discussão que teve por desfecho a morte dos três: Pedro e João Balbino e do Coronel Antônio Sobreira.

A investigação do crime nos desvenda muito mais do que o delito. A leitura de um amplo leque de fontes, nas quais os personagens em litígio e seus familiares deixaram registros de suas existências, ${ }^{3}$ nos coloca frente a frente com fragmentos dos movimentos rurais e dos conflitos ocorridos na zona rural de Juiz de Fora, ao longo de aproximadamente cinqüenta anos

\footnotetext{
${ }^{1}$ Carta encontrada no bolso de Pedro Balbino de Mattos e anexada ao processo de homicídio do Coronel Antônio José Sobreira. Arquivo Histórico de Juiz de Fora (doravante AHJF), Fundo Fórum Benjamin Colucci, Processos Criminais do Período Republicano, Processo de Homicídio, 8 de outubro de 1919.

${ }^{2}$ A cidade de Juiz de Fora está localizada na Zona da Mata mineira e foi a maior produtora de café de Minas Gerais de 1856 até a década de 30 do século passado, concentrando o maior contingente de cativos da Província na segunda metade do século XIX (19.351 em 1872 e 20.905 em 1886).

${ }^{3}$ Para reconstruir as histórias aqui narradas e analisadas, levantei informações em uma multiplicidade de fontes: registros de nascimento, casamento e morte; inventários post-mortem; processos criminais; ações civis diversas (embargo, execução, divisão de terras, tutela) e jornais.
} 
(1878-1928). ${ }^{4}$ Estas histórias serão aqui narradas a partir da constituição da família Balbino de Mattos, das trajetórias desta família e dos Sobreira, revelando suas estratégias de vida, sua teia de relações parentais e clientelares, cumplicidades e desafetos, reciprocidades e conflitos. Elas nos dão a conhecer as conquistas e as derrotas que se forjaram nas vicissitudes da vida e nos desnudam as estratégias de sobrevivência destes indivíduos à luz das demandas judiciais no jogo de poder sobre o direito à terra.

Os dados coletados remontam às primeiras décadas do oitocentos, quando, nas posses de Francisco Garcia de Mattos, um tropeiro que foi senhor de muitos homens e de terras, nasceu o escravo pardo Balbino, lá pelos idos de 1828. As principais fazendas de Garcia de Mattos eram a Boa Vista e a Vargem, e estavam localizadas às margens do Caminho Novo. ${ }^{5}$ Nelas se formou uma comunidade rural composta de escravos, agregados (livres e libertos) e empregados livres pobres. Balbino foi o homem de confiança de seu senhor, arrieiro de suas tropas e administrador de seus bens; fez multiplicar a riqueza do velho tropeiro, que, em reconhecimento dos bons serviços prestados, libertou-o, em 1856, juntamente com sua mulher Carolina e dois filhos, Francisco e Manoel. Os ex-cativos, que permaneceram vivendo nas terras da Boa Vista e adotaram os nomes de Balbino Garcia de Mattos e Carolina Maria de Souza, deram origem à família Balbino de Mattos. ${ }^{6}$

\footnotetext{
${ }^{4}$ De certa forma estou tratando de uma comunidade rural, expressão que está sendo utilizada para designar um grupo de pessoas que habitaram um espaço geográfico específico, a região do atual bairro de Benfica, em Juiz de Fora - Zona da Mata mineira - e as relações por elas constituídas. Este grupo se estabeleceu na localidade de meados do século XIX até as duas primeiras décadas do século XX (1828-1928) e estava ligado por laços pessoais e sociais parentesco consangüíneo e ritual, amizade, vizinhança, trabalho, exploração e dependência permeados cotidianamente pela solidariedade, reciprocidade, tensão e conflito. Definição estabelecida a partir de: John Comerford. "Comunidade Rural", Márcia Maria Menendes Motta (org.), Dicionário da Terra, Rio de Janeiro: Civilização Brasileira, 2005, p. 112-120. As datas-limite correspondem ao ano de morte de Theodora Maria de Souza (1878), deixando legados em terras para seus libertos, e à morte de Manoel Balbino de Mattos (1928), principal personagem da análise.

${ }^{5}$ Caminho Novo: estrada aberta por Garcia Rodrigues Paes, no início do século XVIII, ligando o Rio de Janeiro a Minas Gerais.

${ }^{6}$ A respeito dos nomes, tanto de livres quanto de escravos e forros, e da adoção de sobrenomes compostos de nomes de ex-senhores ou de pais, ver Luiz Felipe de Alencastro, "Dar nomes aos brasileiros: Joaquins, Lycurgos, Rosalindas, Caios, Jeffersons e Bismarcks", (org.), História da Vida Privada no Brasil: Império: a Corte e a modernidade nacional, Coleção dirigida por Fernando A. Novais, São Paulo: Companhia das Letras, 1997, p. 53-59, e Ana Lugão Rios \& Hebe Maria Mattos. Memórias do cativeiro: família, trabalho e cidadania no pós-abolição. Rio de Janeiro: Civilização Brasileira, 2005, p. 91, 157-158.
} 
Na comunidade formada na Fazenda da Boa Vista, cativos, libertos e agregados construíram laços de parentesco - consangüíneo e ritual -, relações de amizade e trabalho que se estenderam através das gerações. Após ser alforriado, Balbino continuou exercendo as atividades de arrieiro da tropa do ex-senhor, mediante um salário de cento e cinqüenta mil-réis anuais, posteriormente elevado para quinhentos mil-réis. ${ }^{7}$ Ele e a esposa, a parda Carolina, que um dia havia sido escrava da segunda esposa de Francisco Garcia de Mattos, tornaram-se senhores de cinco escravos, estabeleceram redes de compadrio extensivas às pessoas livres (incluindo seus ex-senhores) e cativos, ampliaram suas relações sociais entre a escravaria da propriedade de Francisco Garcia de Mattos e por entre a população livre/liberta das proximidades, reproduzindo as estratégias senhoriais, ampliando as alianças e inaugurando suas próprias redes de relações. Em 1864, Balbino Garcia de Mattos faleceu, deixando para a viúva e filhos uma pequena fortuna, estimada em pouco mais de dez contos de réis. ${ }^{8}$ Pouco depois, em 1866, o tropeiro e ex-senhor de Balbino, Francisco Garcia de Mattos, teria o mesmo destino, deixando para os filhos do arrieiro terras e cativos (retirados de sua terça). ${ }^{9}$

Ao longo de suas existências, os antigos senhores de Balbino, Francisco Garcia de Mattos e D. Theodora Maria de Souza, negociaram e legaram partes de terras de suas propriedades; outras tantas partes foram entregues aos herdeiros. Após a morte de Garcia de Mattos, os legatários que moravam

\footnotetext{
${ }^{7}$ AHJF, Fundo Segundo Ofício de Notas, caixa 01, livro s/n, folhas 48-49v, Carta de Alforria, 1/71859. Para que o leitor tenha uma idéia desse montante, informo que as terras da Fazenda da Boa Vista, propriedade de Francisco Garcia de Mattos, possuíam um valor que variava entre $60 \$ 000$ e $100 \$ 000$ o alqueire. As terras da Fazenda Boa Esperança, de Francisco Garcia de Mattos, valiam em média $35 \$ 000$ o alqueire. Os cálculos tiveram por base os documentos seguintes: AHJF, Fundo Primeiro Ofício de Notas, Escritura de compra e venda de terras, Livro $^{\circ} 14$, caixa $\mathrm{n}^{\circ} 2$, fls. $52 \mathrm{v}-53 \mathrm{v}, 26 / 9 / 1870$, e Escritura de compra e venda de terras, Livro $\mathrm{n}^{\circ} 21$, caixa $\mathrm{n}^{\circ} 3$, fls. 10-11, 18/5/1878 e Arquivo Histórico da Universidade Federal de Juiz de Fora (doravante AHUFJF), Fundo Benjamin Colucci, Referência 356, caixa 35B, Inventário post-mortem de Francisco Garcia de Mattos, 30/6/1866.

${ }^{8}$ Para melhor compreensão dos padrões de riqueza em Juiz de Fora, no período em análise, ver Rita de Cássia da Silva Almico, Fortunas em Movimento: as mudanças ocorridas na riqueza pessoal -Juiz de Fora/1870-1920, Dissertação de Mestrado, Campinas: UNICAMP, 2001.

${ }_{9}^{9}$ AHUFJF, Fundo Fórum Benjamin Colucci, Inventário post-mortem de Francisco Garcia de Mattos. Referência: 356, caixa 35B.
} 
distante venderam suas porções à viúva ou a terceiros. ${ }^{10}$ Theodora Maria de Souza faleceu em 1878, sem descendentes ou herdeiros diretos. Em seu inventário, foram avaliados 14 cativos, excluídos os que foram alforriados em testamento e que totalizavam 21. Além destes 35 mancípios, viviam na propriedade os cativos dos órfãos de Balbino Garcia de Mattos (em torno de 12), ${ }^{11}$ os dos agregados Manoel Albano, os de Manoel Quirino da Silva e talvez outros. ${ }^{12}$ Todos os cativos possuíam algum tipo de relação parental dentro do plantel. ${ }^{13} \mathrm{Na}$ Fazenda da Boa Vista as relações familiares estavam presentes no casamento formal, nas relações consensuais, no parentesco ritual. Em suma, a vida nessa propriedade envolvia uma ampla rede de relações comunitárias, estabelecida entre cativos e homens livres. Theodora também determinou que o que sobrasse de seus bens deveria ser dividido em duas partes iguais, uma para a sobrinha Maria Victória, e a outra para os escravos alforriados, preferencialmente em terras.

Nas terras herdadas, os libertos construíram umas poucas benfeitorias, algumas casinhas, geralmente pequenas habitações cobertas de capim; Inácio e Romão, juntamente com suas mulheres, meavam um engenho; Theodora Maria e o marido possuíam um engenho e cercas; nas terras de Francelino, o filho Agostinho construíra uma casinha, e o genro Querubino, um paiol, e

\footnotetext{
${ }^{10}$ A documentação nem sempre menciona a extensão da terra, que é discriminada como "parte" ou "sorte" de terras. Em 1869, D. Theodora vendeu 23 alqueires e uma quarta de terras de cultura na Fazenda Boa Esperança (anexa à Boa Vista), por 1:162\$500 (ver: Escritura de compra e venda juntada ao inventário de Theodora Maria de Souza, fls. 590-594); em 1870, negociou 50 alqueires de terras na Fazenda da Boa Vista com João Carlos Pereira, por 3:000\$000; e, pouco antes de falecer, vendeu mais 50 alqueires de terras na mesma propriedade a João Carlos Pereira, por 5:000\$000 (ver AHJF, Fundo: Primeiro Ofício de Notas, Livro n ${ }^{\circ}$ 14, fls. $52 \mathrm{v}-53 \mathrm{v}$ e Livro $\mathrm{n}^{\circ} 21$, fls. 10-11).

${ }^{11}$ Aqui incluídos os cativos que herdaram dos pais e os que herdaram de Francisco Garcia de Mattos.

${ }^{12}$ Inventário post-mortem de Theodora Maria de Souza e Prestação de Contas da Testamentária. Este inventário nomeia estas pessoas, Manoel Albano, os órfãos e Manoel Quirino, como residentes na fazenda, agregados, beneficiados em testamento por D. Theodora; talvez existissem outros que não foram beneficiados. AHUFJF, Fundo Fórum Benjamin Colucci, Referência: 1660, caixa 228 B, 1878 e referência: 332A05.

${ }^{13}$ Para chegar à reconstituição das famílias existentes no inventário de D. Theodora Maria de Souza, foi necessário cruzar as informações constantes da lista de matrícula (onde apenas os nomes das mães das crianças menores estavam discriminados), com os dados coletados no inventário de Francisco Garcia de Mattos, incluindo também as informações constantes dos assentamentos de casamento e batismo dos escravos de Francisco Garcia de Mattos e D. Theodora Maria de Souza.
} 
a família tinha "plantações de arvoredos" (pomar).$^{14}$ Há evidências de que os libertos de D. Theodora se associavam para a realização de tarefas corriqueiras da lida no campo, como o preparo da terra, a semeadura e a colheita de suas lavouras e a criação de pequenos animais, como porcos, galinhas e também algum gado vacum.

No final dos anos 80 do oitocentos, em razão de muitas vendas e divisões entre herdeiros, a Fazenda da Boa Vista se tornou propriedade de vários condôminos, dentre os quais os prósperos fazendeiros João Carlos Pereira, João Rodrigues de Oliveira, "os libertos" e demais legatários de D. Theodora Maria de Souza, os órfãos do finado Balbino e outros. Nestas circunstâncias, não demoraria muito para que "um xadrez de conflitos" ali se configurasse, transformando as terras da Boa Vista em uma "confusão de limites". ${ }^{15}$ Em outras palavras, as terras legadas estavam em condomínio com homens fortes e poderosos e, nos anos subseqüentes, os libertos tiveram que elaborar estratégias de permanência na propriedade e defender nos tribunais o direito à terra.

As estratégias adotadas pelos grandes proprietários e pelos libertos para garantirem o direito à propriedade foram facilitadas pela indefinição dos limites. Estas querelas me ajudaram a acompanhar algumas das possibilidades destas lutas entre desiguais e os instrumentos com os quais cada envolvido operou para alargar seus espaços de possibilidades: as estratégias dos latifundiários para se apropriarem das terras dos proprietários menores e destes para permanecerem na terra; a argumentação dos operadores da lei para defenderem os interesses de seus clientes - silenciando ou revelando estrategicamente o que melhor atendia às conveniências de cada uma das partes. ${ }^{16}$

Voltando ao nosso objetivo de compreender os assassinatos de 1919, é preciso retornar ao ano de 1893, quando João Carlos Pereira entrou com uma

\footnotetext{
${ }^{14}$ Informações retiradas das escrituras de compra e venda juntadas ao inventário de Theodora Maria de Souza, que, na realidade, é uma ação de divisão e demarcação de terras, mas que foi classificada equivocadamente como inventário pelos organizadores do acervo.

${ }^{15}$ Estas expressões entre aspas foram utilizadas por Márcia Maria Menendes Motta, Nas fronteiras do poder: conflito e direito à terra no Brasil do século XIX, Rio de Janeiro, Vício de Leitura/Arquivo Público do Rio de Janeiro, 1998, p. 84.

${ }^{16}$ Destaco que as histórias aqui narradas não representam "a reconstrução de situações típicas”, mas são elucidativas "para ressaltar os elementos constitutivos de um modelo": Giovanni Levi, A herança imaterial: trajetória de um exorcista no Piemonte do século XVII, Rio de Janeiro, Civilização Brasileira, 2000, p. 99.
} 
ação de divisão e demarcação das terras da Fazenda da Boa Vista.${ }^{17}$ Nesta ação, foram citados como co-proprietários da Boa Vista alguns dos libertos de D. Theodora. Todos os sócios foram citados para apresentarem seus títulos e compartilharem as custas do processo. Nomearam-se os louvados que fariam a medição, a divisão e a demarcação das terras, contrataram o agrimensor e convocaram testemunhas conhecedoras dos marcos das divisas da propriedade. ${ }^{18}$

Medidas e demarcadas as terras, a Fazenda da Boa Vista estava para ser dividida, quando os libertos Manoel Decuada e Antonio Basílio - aos quais não foi atribuída nenhuma parcela de terra na partilha - entraram com uma ação de impugnação. O advogado dos dois alegou que outros condôminos estavam recebendo porções de terras maiores do que haviam provado possuir, que havia duplicidade nos documentos apresentados e que o juiz não havia determinado quais dos títulos eram válidos e que a alguns condôminos haviam sido atribuídas mais terras do que eles tinham reivindicado e provado possuir.

${ }^{17}$ AHJF, Fundo Fórum Benjamin Colucci, Processos Civis, Ação de Divisão e Demarcação de Terras da Fazenda da Boa Vista, 31 de maio de 1893, Referência 2670, caixa 19. Não localizei os outros volumes, contudo, dois documentos que estão sob a guarda do AHUFJF, classificados como "inventários”, de Joaquim José Sobreira e de D. Theodora Maria de Souza, são, sem dúvidas, duas ações ou dois volumes da ação de demarcação de terras da Fazenda da Boa Vista. Foram classificados como inventários por serem estas as peças que estão inicialmente transcritas: os inventários de Joaquim José Sobreira e o de Theodora Maria de Souza. A leitura minuciosa dos documentos, porém, evidencia que se trata da ação de demarcação das terras da Fazenda Boa Vista, sem permitir afirmar se são partes da ação movida em 1893 ou da movida em 1901. De qualquer modo, ambos compõem-se, basicamente, dos traslados de documentos que provam a propriedade dos diversos herdeiros (traslados de inventários e escrituras de compra e venda), sem acrescentar informações substanciais sobre os resultados ou os debates jurídicos relativos a esta demanda especificamente. As referências dos "inventários" são: AHUFJF, Fundo Fórum Benjamim Colucci, Inventários post-mortem de Joaquim José Sobreira, Referência: 705, caixa 94 B; inventário post-mortem de Theodora Maria de Souza, ver nota 12. Não tenho todas as peças deste jogo, visto faltarem alguns volumes das ações, mas ainda que os tivesse, não deixariam de constituir fragmentos e versões. Cabe-me trabalhar com os dados que possuo da melhor maneira possível, ou, como observou Hobsbawm, "formular como tais informações deveriam se encaixar": Eric Hobsbawm, Sobre História, São Paulo: Companhia das Letras, 1998, p. 224.

${ }^{18}$ Ver Regulamento aprovado pelo Decreto $\mathrm{n}^{\circ} 720$, de 5 de setembro de 1890 , para a divisão e demarcação das terras do domínio privado. DEGRETOS DO GOVERNO PROVISÓRIO DA REPÚBLICA DOS ESTADOS UNIDOS DO BRASIL, Rio de Janeiro: Imprensa Nacional, 1890, nono fascículo (de 1 a 30 de setembro de 1890). Há um grande número de ações de divisão e demarcação de terras nos arquivos de Juiz de Fora nos primeiros anos após a proclamação da República, provável resultado das leis que procuravam regular a propriedade da terra, consolidar o mercado de terras e "solucionar os problemas relacionados à titularidade e à valorização do imóvel”, como o Registro Torrens (Decreto n ${ }^{\circ} 451$, de 31 de maio de 1890), Márcia Maria Menendes Motta \& S. R. Mendonça, "Continuidade nas rupturas: legislação agrária e trabalhadores rurais no início da República". Revista Brasileira de Pós-Graduação em Ciências Sociais, Brasília, v. VI, p. 127-147, 2002. 
Estas acusações recaíram, principalmente, sobre o co-proprietário Manoel Balbino de Mattos. De acordo com o defensor, estas irregularidades estavam ocorrendo por não ter o juiz realizado na ação o "despacho de deliberação de partilhas", discriminando quais dos títulos apresentados por cada uma das partes eram hábeis e quais os imprestáveis. ${ }^{19}$

$\mathrm{O}$ advogado de Manoel Balbino contra-argumentou, alegando que Manoel Decuada e Antonio Basílio se haviam apresentado como senhores de "uma ninharia de terras", fundando-se na verba testamentária de D. Theodora Maria de Souza. Ele observou que D. Theodora havia determinado que, após pagas as suas dívidas e cumpridos os seus legados, os remanescentes dos seus bens, se sobrassem, deveriam ser divididos em duas partes iguais entre a sobrinha e os libertos. Contudo, frisou o defensor, sobraram 90 alqueires de terras para a distribuição. Foram legados 74: 12 a Francisco Balbino, 50 a Manoel Albano e 12 a Manoel Quirino. Restaram, deste modo, apenas 16 alqueires de terras, que, somados aos demais bens remanescentes, deveriam ser divididos em duas partes, cabendo uma delas aos libertos. E, ainda, o inventário de D. Theodora não discriminou se as terras estavam na Fazenda da Boa Vista ou na Fazenda da Vargem.

$\mathrm{O}$ advogado continua alegando que o testamento era claro: deveriam ser distribuídos os bens que sobrassem. Mas estes 16 alqueires não estavam na Fazenda da Boa Vista somente e, portanto, não eram válidos os argumentos de Manoel Decuada e Antonio Basílio para impugnar a ação. Passa, a seguir, a fazer contas: a sesmaria da Boa Vista originalmente possuía 225 alqueires; partes destas terras foram entregues aos herdeiros de Francisco Garcia de Mattos, por ocasião de seu falecimento (1866), sendo que só ao herdeiro Manoel Marianno coube mais de $1 / 4$ da dita sesmaria (aproximadamente 56 alqueires). D. Theodora havia vendido 100 alqueires das terras a João Carlos Pereira e legado 74 alqueires por verba testamentária; 10 alqueires foram leiloados para pagamento de direitos e custas do inventário. Portanto, só até aqui haviam sido distribuídas mais terras do que as que originalmente existiam (ou seja, foram distribuídos 240 alqueires de terras onde só havia 225).

Finalmente, o advogado sugere que as terras a serem dadas aos libertos deveriam ser as da Fazenda da Vargem, que continuavam indivisas. Antes,

\footnotetext{
${ }^{19}$ Ver artigos 60 e 61 do Decreto $n^{\circ} 720$, de 5 de setembro de 1890, op. cit., que delibera sobre Divisão de Terras. Estes artigos estabelecem que, após verificar se a homogeneidade da terra não determina variação de preços, o juiz indicava que títulos apresentados pelas partes eram hábeis para serem atendidos e desta decisão não poderia haver recursos.
} 
contudo, pondera que deveria ser promovida nova partilha, considerando-se os 16 alqueires de terras que haviam sobrado de fato, e não 22, como ocorreu por ocasião do inventário de D. Theodora. Alega, ainda, que os libertos ocupavam terras nas duas propriedades (Boa Vista e Vargem) e que só haviam sido tolerados na Boa Vista até então por estarem suas terras indivisas. ${ }^{20}$

A ação de divisão de terras de 1891 não foi homologada e as terras da Fazenda da Boa Vista continuaram em comum, sendo cenário de novo conflito em 1898. Morto João Carlos Pereira sem obter a divisão das terras, elas passaram a pertencer à sua filha e ao genro - José Rodrigues de Oliveira e Silva. Este último, em 1898, entrou com uma ação de despejo contra outros libertos. ${ }^{21}$ $\mathrm{O}$ autor alegou que os forros estavam colocando umas cabeças de gado em suas terras e ocupando indevidamente casas que lhe pertenciam sem pagar aluguel algum. ${ }^{22} \mathrm{O}$ advogado dos réus defendeu que as ditas casas haviam sido construídas às suas custas e que as terras lhes pertenciam, pois "a fazenda da Boa Vista, como a da Vargem, continuam em comum em toda a área, tendo havido tentativa de divisão (...) em 1893" e que, portanto, o autor "não pode negar o direito por domínio e posse dos réus no terreno e casa em questão, ali como condôminos e aqui como senhores exclusivos". ${ }^{23}$ Havia, ainda, irregularidades na ação (a mulher do autor, que não foi citada, assim como o marido ausente de Thereza, sem representante legal na ação). ${ }^{24}$

Uma série de testemunhas depõe, informando que as terras da propriedade continuavam em comum; que os réus ocupavam terrenos ora na Fazenda da Boa Vista ora na Fazenda da Vargem; que Manoel Decuada e a mulher moravam na Fazenda da Vargem e, depois que fizeram negócios com Manoel Balbino, passaram para a Fazenda da Boa Vista; houve quem alegasse que ambas as fazendas eram anexas, mas suas divisas eram conhecidas e respeitadas, e os que afirmaram que as divisas eram conhecidas, mas não respeitadas. Alguns asseguram que trabalharam nas construções das casas, objeto da demanda,

\footnotetext{
${ }^{20}$ AHJF, Fundo Fórum Benjamin Colucci, Processos Civis, Ação de Divisão e Demarcação de Terras da Fazenda Boa Vista, 31 de maio de 1893, fls. 1010-1013.

${ }^{21}$ Manoel Decuada, José Marcelino, Maria Cota, Manoel Theodoro, Antonio Basílio e Thereza de Tal, ex-cativos e legatários de D. Theodora Maria de Souza.

${ }^{22}$ AHJF, Fundo Fórum Benjamin Colucci, Processos Civis, Ação Ordinária. Referência: 3363, de 18 de abril de 1898, Caixa 80, fls. 2f/v.

${ }^{23}$ Idem, fl. 16.

${ }^{24}$ Contrariando as Ordenações Filipinas, Livro III, Título XLVII, que reza que nenhum homem ou mulher casado pode litigar em Juízo sobre bens de raiz sem a outorga do cônjuge. Disponível em <http://www.uc.pt/ihti/proj/filipinas/13p631.htm>. Acessado em 22/08/2003.
} 
recebendo do autor pelos serviços prestados, e outros que receberam dos réus. A testemunha Francisco José Rezende Franco comentou

(...) que os réus depois da morte de $\mathrm{D}$. Theodora foram residir a principio na Fazenda da Vargem e aí se demoraram por algum tempo, depois Manoel Balbino de Mattos foi comprando partes de terras e benfeitorias d'eles pelo que foram os mesmos se mudando para a Fazenda da Boa Vista. N'essa ocasião a testemunha que era condômino da Boa Vista não se opôs a que eles aí se estabelecessem porque a Fazenda estava em comum entre vários co-proprietários. ${ }^{25}$

Testemunho similar é fornecido por Antonio Bianco (ou Antonio Labanca), que possuía seis alqueires de terras na Fazenda da Boa Vista, posteriormente vendidos ao autor. Disse que "nunca se opôs a que aí residissem [os libertos] porque a terra continha mais do que os seis alqueires e eles diziam que eram também donos". ${ }^{26}$ Finalmente, o autor desta ação desistiu da intenção sobre as terras, insistindo somente sobre as casas, nas quais os réus residiam havia mais de 10 anos. O juiz considerou a ação improcedente e, mais uma vez, os libertos permaneceram nas terras da Boa Vista.

Em junho de 1901 José Rodrigues de Oliveira e Silva moveu nova ação de demarcação e divisão das terras da Fazenda da Boa Vista. Foram nomeados condôminos diversos membros da família Sobreira, Manoel Balbino de Mattos e alguns dos herdeiros de D. Theodora Maria de Souza. ${ }^{27}$ Neste ponto da análise, possuo algumas pistas para compreender como os libertos continuavam sendo citados como condôminos da Fazenda da Boa Vista, embora as evidências demonstrem que, ao longo dos anos, eles se desfizeram de suas terras.

Em 1901, as terras da Fazenda Boa Vista foram demarcadas e partilhadas. Alguns dos libertos não pagaram as custas da ação e tiveram seus bens - suas terras - seqüestrados para penhora. De Theotonio foram arrebatados dois al-

${ }^{25}$ AHJF, Fundo Fórum Benjamin Colucci, Processos Civis, Ação Ordinária. Referência: 3363, de 18 de abril de 1898 , caixa $80,114 \mathrm{f} / \mathrm{v}$.

${ }^{26}$ Idem, fl. 117.

${ }^{27}$ Os libertos citados foram: Manoel Decuada e sua mulher Ricarda; Manoel Theodoro de Souะa e Romão Theodoro, seu filho Mariano e seus genros (os maridos de Faustina e de Esméria); Theotonio e suas filhas Bernardina (representada pelo marido) e Thereza (cujo marido estava ausente havia mais de seis anos) e os herdeiros do "compadre Manoel Albano" (ou Manoel Ignácio Fernandes): AHJF, Fundo Fórum Benjamin Colucci, Processos Civis, Ação de Divisão e Demarcação de Terras da Fazenda da Boa Vista. Referência: 4106, caixa 18, de 10 de junho de 1901. Possivelmente, este é o primeiro volume da ação, pois está encerrado com a abertura dos trabalhos de medição. Não localizei os outros volumes, contudo, encontrei ações de execução que evidenciam ter sido a ação de demarcação encerrada em 1903-1904, e que me permitiram acompanhar alguns desdobramentos da questão. 
queires e sete centímetros de terras de cultura em matas. Em 1905, esta dívida foi executada, e as terras foram vendidas. O valor arrecadado com a venda dos bens não foi suficiente para cobrir a totalidade do débito com as custas da ação de divisão de terras e da ação de execução. Em suma, Theotonio tornou-se um sem-terra e um "com dívidas". ${ }^{28}$ Os outros libertos executados foram Manoel Theodoro de Souza (que aparentemente pagou a dívida), José Marcelino e Romão Theodoro de Souza. Os dois últimos também foram executados e tiveram o mesmo destino de Theotonio. Apesar de terem tido os seus direitos garantidos, pois foram reconhecidos como co-proprietários da Fazenda da Boa Vista, em sua maioria os libertos não tiveram condições financeiras para pagar as custas da ação e acabaram perdendo a terra nos anos de 1904-1905. ${ }^{29}$

Ao estudar os conflitos de terras em Paraíba do Sul, Márcia Motta comenta que

(...) os grandes fazendeiros se apropriam da legislação não porque as leis satisfazem inteiramente os seus interesses, mas porque eles possuem recursos para financiar processos custosos, recompensando satisfatoriamente os defensores de sua versão nos tribunais. ${ }^{30}$

No caso em análise, vimos que, mesmo saindo com os seus direitos assegurados em todas as ações, inclusive na ação aberta em 1901, que dividiu e partilhou as terras da Boa Vista, os forros não puderam garantir a propriedade de suas nesgas de terras, que foram seqüestradas para o pagamento dos gastos com a ação de divisão e de execução de dívidas, evidenciando a dissociação entre direitos, leis e justiça.

É possível, finalmente, apresentar algumas hipóteses para parte das questões que permeiam a narrativa. A comunhão da terra e a indefinição dos limites da propriedade de cada um dos condôminos favoreceram a permanência dos ex-cativos na Fazenda da Boa Vista sem maiores contestações, pelo menos inicialmente. É provável que os demais condôminos tivessem interesses em, de alguma forma, se apropriar das terras dos libertos, mesmo que

\footnotetext{
${ }^{28}$ A custa da ação de divisão de terras ficou em $139 \$ 162$ para cada condômino; os bens de Theotonio foram vendidos por $324 \$ 500$ e as custas da ação de execução foram avaliadas em $390 \$ 470$, ou seja, Theotonio permaneceu devedor dos $139 \$ 162$ das custas da ação de demarcação e de mais $65 \$ 970$ do que ficou a dever desta ação de execução.

${ }_{29}$ AHJF, Fundo Fórum Benjamin Colucci, Processos Civis, Ação de Execução de 18 de outubro de 1904, caixa ${ }^{\circ}$ 58. São três ações, todas na mesma data e caixa; Autor José Rodrigues de Oliveira e Silva e réus Manoel Theodoro de Souza, Theotonio José Vieira e José Marcelino Martins.

${ }^{30}$ Márcia Maria Menendes Motta, op. cit., p. 21 (ênfase no original).
} 
a quantidade destas fosse insignificante. As informações evidenciam algumas estratégias dos forros para permanecerem na propriedade. Ao venderem uma porção de terra, normalmente por escritura particular ou direito hereditário, eles se mudavam para outra área, dentro de uma das ex-propriedades de D. Theodora (Boa Vista ou Vargem). Assim, os anos passavam e eles continuavam nas fazendas. Este fato pode ter facilitado a permanência na terra e gerado as confusões a respeito de suas reais propriedades e limites. Por algum tempo, foi possível permanecer na terra, até que os condôminos mais fortes exigiram a divisão da propriedade, tornando-os vulneráveis. O certo é que eles também operaram com a indefinição de limites.

Os libertos de D. Theodora perderam suas nesgas de terras, mas Manoel Balbino de Mattos, também afro-descendente, teve possibilidade diversa - tornou-se senhor de muitas terras, teve recursos para pagar bons advogados, defender sua versão e garantir suas propriedades. Mas mesmo ele foi alvo e vítima da cobiça de seus vizinhos mais poderosos, os Sobreira.

\section{Demandas judiciais no jogo de poder sobre o direito à terra}

Ao longo dos anos, desenvolveu-se nas proximidades da Fazenda da Boa Vista um povoado que recebeu o nome de uma grande propriedade dos arredores, Benfica. Na seção anterior, localizei a área de conflito e demonstrei a tensão entre os personagens em litígio, o que me permite retomar o ato de violência que, em 1919, evidenciou o conflito velado que há anos envolvia as famílias Balbino de Mattos e Sobreira.

$\mathrm{Na}$ estação de Benfica, João e Pedro Balbino de Mattos ${ }^{31}$ abordaram o Coronel Antônio José Sobreira. As partes discutiram, houve agressão e Pedro e João deixaram o Coronel Antônio Sobreira gravemente ferido. Enquanto era conduzido ao hospital, e os Balbinos tentavam fugir, os familiares do Coronel foram avisados do ocorrido por telefone. Um de seus filhos e alguns de seus camaradas dirigiram-se ao local do conflito e se juntaram ao grupo de populares que perseguiam os agressores. Ao encontrá-los, dispararam contra eles, matando-os. Mesmo depois de mortos, Pedro e João foram novamente vítimas da ira de camaradas de seus algozes, que atiraram impiedosamente

\footnotetext{
${ }^{31}$ Pedro era filho de Francisco Balbino de Mattos e genro de Manoel Balbino de Mattos; João
} era filho de Manoel Balbino de Mattos. 
sobre seus cadáveres. O Coronel Sobreira também faleceu a caminho do hospital de Juiz de Fora. ${ }^{32}$

No bolso de Pedro Balbino de Mattos foi encontrada a carta que abriu este artigo, dirigida ao tio/sogro, Manoel Balbino, e ela aponta as razões do crime. Reconstituindo os acontecimentos de maneira linear, ficamos sabendo que a divisão das terras da Fazenda da Boa Vista, em 1901-1904, não pôs fím aos conflitos entre seus vários condôminos. Em 1919, o Coronel Sobreira, vizinho de Manoel Balbino de Mattos, mandara um gado para os pastos do velho Major; a princípio, parece que sem sua autorização. Ciente deste fato, Pedro Balbino abordou o Coronel, a fim de esclarecer a situação, ao que o rico fazendeiro teria respondido que "não tinha que dar satisfação a negro". ${ }^{33}$ A resposta do Coronel Sobreira originou uma discussão que resultou em violência. Ouvido como testemunha, Manoel Balbino Filho alegou não saber por que o Coronel mandou o gado para os pastos de seu pai; seu irmão Francisco disse que desfrutava dos pastos com autorização do pai e por isto os alugara ao Coronel Sobreira. O Major Manoel Balbino afirmou que não autorizou a colocação de gado em seus pastos e que ignorava que algum de seus filhos os tivesse alugado e informou que ele e seus filhos tinham relações amistosas com o Coronel Sobreira, e que

(...) se é certo que o cumprimentava, entretanto, sempre o evitava e isto porque, sendo um homem acismado ( $\mathrm{sic}$ ), via no coronel Sobreira uma pessoa que gostava de prejudicar os outros, como fazia ao próprio depoente, de quem desfrutava há mais de quinze anos uns pastos a si pertencentes; que tentou, por muitas vezes, fazer amigavelmente com o Coronel Sobreira a aviventação $0^{34}$ das suas divisas com ele e para assim evitar que permanecesse esse seu prejuízo, tudo, porém, em pura perda, que o Coronel Alfredo Mendes chegou a pedir procuração ao depoente para fazê-la judicialmente, mas o depoente negou-se a dá-la para evitar questões.

\footnotetext{
${ }^{32}$ AHJF, Fundo Fórum Benjamin Colucci, Processos Criminais do Período Republicano, Processo de Homicídio, 8 de outubro de 1919.

${ }_{33}^{3}$ No depoimento de Manoel Balbino de Mattos, ele alega ter recebido a notícia dos acontecimentos de 8 de outubro de 1919 por um professor, seu vizinho, que disse ter ouvido esta frase de uma pessoa que estava presente no momento da discussão. Nenhuma das testemunhas do processo fez alusão a isto. Esta frase foi relembrada pelo sr. Hélio Balbino de Mattos, neto de Manoel Balbino de Mattos e por d. Almerinda, neta de um antigo empregado dos Sobreira, em entrevista que me concederam recentemente.

${ }^{34}$ Aviventação: ato de restabelecer ou reparar linhas limítrofes confusas ou falhas; fixar limites: Donaldo J. Felippe, Dicionário do Advogado, Campinas (SP), Julex Livros S.A., 1992, p. 72.
} 
Finalmente, disse acreditar que, se ele tivesse pedido, por certo o Coronel Sobreira teria retirado os animais de suas terras sem violência. Se subtrairmos de 1919, ano do triplo assassinato, os 15 anos durante os quais o Coronel Sobreira ocupava as terras de Manuel Balbino, segundo o depoimento deste, sem a sua autorização, chegamos ao ano de 1904, exatamente quando se findou a ação de demarcação das terras da Fazenda da Boa Vista. Portanto, percebe-se que, mesmo sendo reconhecido como proprietário das terras e possuindo maiores recursos econômicos e prestígio social que os demais libertos, o Major Manoel Balbino de Mattos enfrentou longos anos de conflito velado com o Coronel Sobreira, que desrespeitava os limites de sua propriedade e nela introduzia seu gado. Não obstante ter afirmado crer que, se pedisse, o Coronel retiraria o gado de suas terras, ele mesmo informa que o desafeto usufruía havia mais de 15 anos dos pastos de sua propriedade, e que foram em vão suas tentativas de resolver a questão amigavelmente. A ocupação de novas áreas, ao que parece, agravou o conflito, levando Pedro Balbino a "vingar-se ou morrer", visto julgar-se com os mesmos direitos de outros homens.

A imprensa juizforana noticiou os fatos, do momento de seu acontecimento ( 8 de outubro de 1919) até a finalização do inquérito (13 de outubro de 1919), ${ }^{35}$ dando grande destaque aos "lamentáveis sucessos de Benfica". Todos os noticiários divulgaram o delito, não apenas porque uma das vítimas, o Coronel Antonio Sobreira, era um rico fazendeiro do município, mas também pela barbaridade com que Pedro e João foram assassinados pelo filho da vítima. Os jornais consideraram estes últimos homicídios como uma aplicação sumária da "Lei de Lynch". ${ }^{36}$

A imprensa manifestou repúdio à ação da polícia, chamando-a de negligente. De acordo com os noticiários, o delegado, ao chegar a Benfica e encon-

${ }^{35}$ Dos jornais que circulavam na época, O Pharol e o Jornal do Commercio, estão faltando os exemplares exatamente nos dias próximos ao delito; o jornal Diário Mercantil noticiou, a partir do dia 9 de outubro; do jornal Correio de Minas falta o exemplar do dia 9 de outubro; o fato foi noticiado nos dias seguintes, até o fim do inquérito; o jornal Diário da Tarde noticiou a partir do dia 8 de outubro; $O$ Dia noticiou entre os dias 9 e 13 de outubro. Biblioteca Municipal Murilo Mendes (doravante BMMM).

36 "Do inglês Lynchs law ou lynch law, daí linchamento. Etimologia incerta, proveniente do verbo to linch, bastonar, bater com pau, ou do nome Lynch, de um juiz irlandês que, por volta de 1943, mandou enforcar o próprio filho. Outro Lynch, do século XVII, na área de Kentucky, punia severa e discricionariamente os assaltantes que infestavam a região. A História registra mais três personagens de nome Lynch, todos eles rudemente empenhados na luta contra o banditismo ou adversários políticos”. Disponível em <http://www.direitovirtual.com/latim/ lei_de_lynch.htm>. Acessado em 15/02/2003. 
trar os agressores do Coronel Sobreira mortos, mandou entregar os corpos às famílias, e o enterro ocorreu sem que se realizasse o exame de corpo de delito. Não foram inquiridas testemunhas no local do crime, dando tempo "a que se preparasse a defesa quem quisesse fazer". ${ }^{37} \mathrm{~A}$ imprensa também repudiou a ação de Sobreira Filho, que assassinou barbaramente os Balbinos de Mattos e que se evadiu após o ato. O Correio de Minas assim se manifestou:

A barbaridade de que se revestiu a morte dos dois [Pedro e João] tira ao caso sua primitiva feição de justo desforço filial [danificado] já se encontravam presos e desarmados quando foram mortos, ou melhor, trucidados por uma turba que não só se limitou a matar, mas ainda se entregou a excessos brutais, que a justiça há de saber castigar. ${ }^{38}$

Os noticiários qualificaram Pedro e João como pessoas modestas e estimadas pela sua "honradez e probidade", sendo assim considerados pela população de Benfica, onde residiam havia muitos anos. O Diário Mercantil os chamou de "fazendeiros". Manoel Balbino de Mattos, ou melhor, o Major Manoel Balbino de Mattos, foi qualificado como um "adiantado fazendeiro e também muito querido". Quanto ao móvel do delito, mencionam questões de terras e uma demanda entre o Coronel Antonio Sobreira e Manoel Balbino, que estaria, naquele tempo, aguardando solução pelo Tribunal do Estado. ${ }^{39}$ Os camaradas de Sobreira Filho foram despronunciados e ele, absolvido, em 22 de março de 1920, por ter o júri considerado, por unanimidade, que se encontrava "em estado de completa privação de sentidos e de inteligência no ato de cometer o crime". ${ }^{40}$

$\mathrm{Na}$ ocasião em que saiu a sentença absolvendo Sobreira Filho, as viúvas de Pedro Balbino e João Balbino e seus filhos deram início a uma "ação ordinária indenizatória de dano material". A ação movida pela esposa de Pedro exigia uma indenização no valor de 200:000\$000. Para avaliar o dano, considerou-se a idade de Pedro Balbino (45 anos aproximadamente), a expectativa de vida (60 anos) e a atividade exercida por ele, "vivendo como vivia da exploração de uma casa de aves no Rio, negócio muito rendoso, que lhe deixaria um lucro

\footnotetext{
${ }^{37}$ BMMM, Jornal O Correio de Minas, "As ocorrências de Benfica”, dia 11 de outubro de 1919. ${ }^{38}$ Idem.

${ }^{39}$ BMMM, Jornal O Dia, 9 de outubro de 1919. Não sei exatamente a qual ação o jornal se refere, pois Manoel Balbino, no depoimento acima, disse que não entrara em demanda com o Coronel Sobreira por ele ocupar suas terras. Mas havia, sem dúvida, por ocasião desse crime, uma ação executiva, movida por Manoel Balbino, envolvendo a família Sobreira.

${ }^{40}$ AHJF, Fundo Fórum Benjamin Colucci, Processos Criminais do Período Republicano, Processo de Homicídio, 8 de outubro de 1919.
} 
líquido anual, fora despesas e retiradas, de 10 contos de reis". ${ }^{41}$ Os advogados dos autores defenderam a tese de que a absolvição na alçada criminal não isentava o réu de responder e ser punido no civil por seu ato, indenizando a família de sua vítima, pois, se o júri criminal por um lado justificou o delito, por outro reconheceu o seu autor - Antônio Sobreira Filho.

$\mathrm{O}$ advogado de Sobreira Filho apresentou diversas testemunhas, que declararam que Pedro havia vendido o comércio no Rio de Janeiro e se mudado para as terras do sogro; que era pessoa de modestíssima condição social e que não possuía bens. $\mathrm{O}$ advogado questionou: se Pedro não tivesse morrido e se fosse condenado pela morte do Coronel Sobreira, como iria sobreviver sua família? E ele mesmo argumentou que por certo sobreviveria por si, uma vez que a mulher e os filhos dele trabalhavam. Esta batalha jurídica estendeu-se até o ano de 1926. Em primeira instância, os herdeiros de Pedro Balbino ganharam parcialmente a causa. $O$ juiz considerou justo que a família recebesse uma indenização, mas avaliou o valor pedido como abusivo. A indenização foi arbitrada em aproximadamente 10:000\$000, mas as partes apelaram desta decisão.

Os defensores de Sobreira Filho insistiram na tese de que ele não tinha a obrigação de indenizar os familiares de sua vítima, uma vez que seu ato fora cometido em uma ocasião de loucura momentânea, provocada pela própria vítima. O advogado da família Balbino de Mattos defendeu a tese de que Sobreira Filho matara Pedro Balbino antes mesmo de ter notícia de que seu pai estava morto; que a morte de Pedro Balbino e João Balbino tornou perempta ${ }^{42}$ a ação criminal contra eles, pelo assassinato do Coronel Sobreira, mas que, se eles tivessem ido a julgamento, teriam a chance de ser inocentados. O Acórdão da Relação Estadual deu ganho de causa a Sobreira Filho, entendendo que ele não teria que indenizar em nada os herdeiros de Pedro Balbino. O advogado apelou, pela viúva e filhos, ao Tribunal Federal e a ação teve resultado final em 1926, com a confirmação do Acórdão de Belo Horizonte.

Deixo de lado a batalha jurídica, mas dela extrairei algumas informações, relevantes, contidas nas alegações do advogado dos Balbinos de Mattos:

Entre o coronel Antonio José Sobreira e o major Manoel Balbino de Mattos havia uma desinteligência antiga provocada por comunhão de terras, entre eles e outros condôminos, e vindo agindo isoladamente o primeiro. De gênio violento

\footnotetext{
${ }^{41}$ AHJF, Fundo Fórum Benjamin Colucci, Processos Civis, Ação ordinária, Referência 2561 e 2562, caixa 15, 22 de março de 1920.

${ }^{42}$ Perempta: "é a perda do direito de continuar a ação, promovida por queixa, ficando paralisado o processo sem motivo justificado por mais de trinta dias": Donaldo J. Felippe, op. cit.
} 
e autoritário, o coronel Antonio José Sobreira não conhecia peias à vontade quando a sua cobiça ambicionava maiores tratos de terra, em que pusesse a pastar centenas de cabeças de gado, que diariamente comprava e diariamente vendia. Tinha [ilegível] predileção pelas comunhões e muito apreciava lidar com os fracos e viúvas aos quais subjugava pelos mil e um enredos em que era fértil seu engenho. Daí uma serie de demandas suas nesta comarca e não menor numero de desafetos e ódios.

Era adquirir uma parte em qualquer condomínio, mínima que fosse ela, em seguida ocupa-lo todo, usufruindo-o sozinho, sem intervenção dos donos aos quais impunha seus desejos.

O major Manoel Balbino de Mattos não era mais feliz que os outros e vivia se queixando ao coronel Sobreira das incursões de seu gado nas terras de sua posse, sem que lograsse qualquer iniciativa desse, que pusesse fim àquelas invasões. Queixar-se era instigar. E assim vinha decorrendo. ${ }^{43}$

Uma rápida visita pelos arquivos locais evidencia que os argumentos do advogado não eram infundados, pois a família Sobreira era assídua freqüentadora dos tribunais da justiça. Os irmãos Sobreira, principalmente Antônio José Sobreira e Joaquim José Sobreira, eram grandes demandistas. ${ }^{44}$ O Coronel Antônio Sobreira alcançou prestígio e fortuna, foi senhor de muitas terras e milhares de cabeças de gado.

O inventário do Coronel Antônio José Sobreira, aberto pouco após sua morte (em 7 de novembro de 1919) e o mapeamento das ações judiciais nas quais ele e o irmão se envolveram parecem confirmar as afirmações do advogado dos Balbinos de Mattos, de que ele "tinha [ilegível] predileção pelas comunhões e muito apreciava lidar com os fracos e viúvas" e que sua estratégia para ampliar suas posses "era adquirir uma parte em qualquer condomínio, mínima que fosse ela, em seguida ocupá-lo todo”. O inventário informa que o Coronel possuía benfeitorias, muito gado (1.388 cabeças de gado vacum) e terras nas seguintes propriedades: Fazenda Benfica, Fazenda Espírito Santo, Fazenda Vista Alegre, Fazenda do Mandembo, Fazenda Campo Grande, Fazenda da Ponte do Pires, Fazenda da Vargem, Fazenda Contendas e Fazenda Santa Cruz - todas estas em Juiz de Fora, e eram propriedades vizinhas. As fronteiras entre elas eram fluidas exatamente para permitir a ocupação irregular do pretenso proprietário.

\footnotetext{
${ }^{43}$ AHJF, Fundo Fórum Benjamin Colucci, Processos Civis, Ação ordinária, Referência 2561 e 2562, caixa 15, 22 de março de 1920 .

${ }^{44}$ A atuação dos irmãos Sobreira e suas estratégias para alargar suas fronteiras serão objeto de um outro artigo que estou desenvolvendo, sendo inviável detalhá-las nos limites deste texto.
} 
Em algumas das fazendas, ele possuía pequenas porções de terras, algo em torno de três ou doze alqueires. Em outras, possuía 80, 130 ou 140. Não foi possível saber exatamente a extensão das terras do Coronel Antônio José Sobreira, porque, em alguns casos, elas não foram discriminadas (apenas há menção a partes ou sortes de terras), mas até onde foi possível somar, encontrei 542 alqueires. Além das propriedades mencionadas, possuía um terreno urbano e uma propriedade em Itabira do Mato Dentro.

É certo que o Coronel Sobreira tinha lá seus desafetos. Em setembro de 1900, por exemplo, há indícios de uma tentativa de assassinato contra ele. Pedro Arcanjo, a quem foi imputada a autoria de vários crimes, declarou que recebera uma proposta para assassinar o Coronel, afirmando que em Benfica pretendiam liquidar com ele. ${ }^{45}$

Aos poucos, a partir da reconstituição dos fatos que apresentei até este momento, é possível compreender como, através dos anos, as terras da Fazenda da Boa Vista se tornaram espaço de cobiça, de indefinição de limites e local de litígio. Retrocedendo no tempo, acompanhamos esta evolução. A Fazenda da Boa Vista primeiramente apareceu na documentação coligida como situada no distrito de Chapéu D’Uvas, isto no ano de 1848. Nessa época, o lugarejo que viria a ser a Vila de Santo Antonio do Paraibuna, e, depois, Juiz de Fora, pertencia à cidade de Barbacena, e assim também Chapéu D'Uvas, um dos povoados mais antigos da região, surgido às margens do caminho de Garcia Rodrigues.

Em 1850, Juiz de Fora se emancipou de Barbacena, sendo elevada a Vila. Dentre os distritos do novo município, encontrava-se Chapéu D'Uvas, ficando a Fazenda da Boa Vista dentro dos limites do distrito sede. ${ }^{46}$ A partir de 1856, o município de Juiz de Fora se destacaria como o principal centro produtor da rubiácea de Minas Gerais. Mas nem só de café vivia Juiz de Fora. Embora a característica agroexportadora da economia juizforana fosse a dominante, a região possuía uma significativa diversificação econômica: produção

\footnotetext{
${ }^{45}$ Esta informação foi retirada do auto de perguntas feitas a Pedro Arcanjo a respeito da morte de Pachoal Gravini. Embora o processo seja relativo ao assassinato de Gravini, Arcanjo foi inquirido sobre as diversas acusações delituosas que lhe eram atribuídas, inclusive a de ter tentado matar o Coronel Sobreira: AHJF, Fundo Benjamin Colucci, Processos Criminais do Período Republicano, Processo de Homicídio, 4 de outubro de 1900.

${ }^{46}$ Em 1850, quando Santo Antonio do Paraibuna (Juiz de Fora) se emancipou de Barbacena, os limites da paróquia de Santo Antonio iam da Fazenda de São Mateus até o final da fazenda de Francisco Garcia de Mattos - o velho; ver Albino Esteves, Álbum do Município de Juiz de Fora, Belo Horizonte: Imprensa Oficial, 1915, p. 54.
} 
de alimentos, aguardente e pecuária. ${ }^{47}$ As terras ao norte, onde se localizavam as propriedades em litígio, não eram boas para o cultivo do café, que exigia terras de qualidade superior. José Augusto Destro apresenta elementos significativos para a compreensão da referida região. ${ }^{48}$ Segundo o autor, no final do oitocentos e início do século XX, mesmo ainda possuindo condições de reprodução da rubiácea (com aproximadamente $20 \%$ de terras em matas virgens), ${ }^{49}$ o município de Juiz de Fora buscava diversificação econômica. Com as crises conjunturais do café - crise dos preços (1896-1910) e primeira guerra mundial (1914-1918) - ocorreu um maior incremento da pecuária, setor que mais cresceu em Minas Gerais entre 1900-1920. Esta atividade já se vinha desenvolvendo no interior das unidades cafeeiras juizforanas, aproveitando-se em pastos as terras deixadas pela cultura da rubiácea. ${ }^{50}$

Após a década de 20 do século passado, a pecuária tornou-se a principal atividade econômica local. O crescimento desta economia criatória promoveu uma valorização das terras, impulsionando seu maior aproveitamento, atingindo todas as áreas rurais do município, mas principalmente a região de Benfica. ${ }^{51}$ Neste arraial foi fundada, em 23 de abril de 1889, uma feira de gado. Realizava-se o incremento do valor mercantil da terra. ${ }^{52}$

Pode-se entender, portanto, por que estas terras foram alvo de cobiças e conflitos - situavam-se em importante região agropecuária e eram fundamentais para as invernadas. Jesus de Oliveira, que viveu por 16 anos em Benfica, escrevendo no Jornal e na Revista $O$ Lince, recorda que a Feira de Gado de Benfica recebia "rezes que eram aos milhares por mês, vindas do sertão de

${ }^{47}$ Sonia Souza, "Além dos Cafezais: produção de alimentos e mercado interno em uma economia agroexportadora - Juiz de Fora na segunda metade do século XIX”, Dissertação de Mestrado, Niterói, UFF, 1998, p. 46.

${ }^{48}$ José Augusto de Souza Destro, "Do café para o leite: a pecuária como alternativa econômica ao café (1896-1940)", Monografia do Curso de Especialização em História de Minas Gerais, Juiz de Fora, UFJF, 2002.

${ }^{49}$ A respeito da disponibilidade e dos tipos de terras, em Juiz de Fora, no pós-abolição, ver também os seguintes autores: Rita Almico, op. cit.; Anderson Pires, "Capital Agrário, investimento e crise da cafeicultura de Juiz de Fora (1870-1930)”, Dissertação de Mestrado, Niterói, UFF/ICHF, 1993, e Luiz Fernando Saraiva, "Um correr de casas, antigas senzalas: a transição do trabalho escravo para o livre em Juiz de Fora - 1870-1900”, Dissertação de Mestrado, Niterói, UFF, 2001.

${ }^{50}$ João Fragoso discorre com detalhes sobre a utilização da terra nas lavouras cafeeiras (uso extensivo) e seu posterior abandono, formando-se capoeiras e pastos. Para maiores informações, ver João Luis Ribeiro Fragoso, "Sistemas Agrários em Paraíba do Sul (1850-1920) - um estudo de relações não-capitalistas de produção", Dissertação de Mestrado, Rio de Janeiro, UFRJ, 1983.

${ }^{51}$ José Augusto de Souza Destro, op. cit., passim.

${ }^{52}$ Idem, p. 42. 
Minas, conduzidas até ali a pé e a cavalo, por sertanejos que usavam chapéus de couro". Outras boiadas eram conduzidas por "jecas com atitudes de bravos". A Feira atraía marchantes do Rio de Janeiro que ali acorriam para comprar boiadas de 5.000, 10.000 cabeças ou mais. O arraial era palco de brigas constantes entre benfiquenses e boiadeiros. O local era freqüentado por larápios, como o João da Thomázia, natural de Paraíba do Sul, que por ali aparecia e agia vez por outra. ${ }^{53}$

Em síntese, as terras da Fazenda da Boa Vista localizavam-se em uma região que, em fins do século XIX e início do XX, sofreu gradual valorização, devido à importância econômica conferida em função da criação de gado e das invernadas. Em conseqüência, tornou-se objeto da cobiça dos homens e espaço de tensões.

Como visto, Pedro e João Balbino vingaram-se das humilhações que o Coronel Sobreira, havia anos, infringia à sua família, principalmente ao velho Major Manoel Balbino de Mattos. Tal ousadia foi paga com a vida, sendo assassinados pelo filho do Coronel e tendo seus cadáveres violados pelos capangas, que sequer foram denunciados. Sobreira Filho foi absolvido, tanto da ação criminal que a justiça pública moveu contra ele como da ação cível impetrada pelas viúvas de Pedro e João. Mas o círculo vicioso das vinganças não teve fim e Manoel Balbino viveria ainda para ver mais um filho assassinado e um neto aleijado por familiares dos Sobreiras. Os conflitos originários da briga pela posse de terras se disseminaram em rixas que redundaram em novos crimes de sangue, segundo testemunhas, em vingança do assassinato de $1919 .{ }^{54}$

As informações recuperadas evidenciam que as terras na região de Benfica eram valorizadas, dificultando as possibilidades de permanência de comunidades negras de libertos na região, ou melhor, a propriedade localizava-se em uma área que sofreu valorização econômica à medida que se tornou importante para a crescente criação de gado e para as invernadas. $\mathrm{Na}$ região paulista, objeto de análise de Maria Helena Machado, a autora concluiu que os libertos conseguiram estabelecer-se com sucesso nas regiões economicamente insignificantes ou decadentes, em áreas desvalorizadas, nas quais as camadas dominantes não se interessavam pelo controle do acesso à terra. Nas áreas com

\footnotetext{
${ }^{53}$ O jornal O Lince foi fundado por volta de 1912, nos subúrbios de Benfica, por Jesus de Oliveira; ver Adail de Oliveira, Coletânea da Saudade, Juiz de Fora: Edição do autor, 2001, p. 134-135. ${ }^{54}$ AHJF, Fundo Fórum Benjamin Colucci, Processos Criminais do Período Republicano, Processo de Homicídio, 17 de julho de 1924.
} 
potencial de valorização, os libertos permaneceram nas terras até o momento em que elas se valorizaram, após o que se tornaram objetos de uma série de conflitos. ${ }^{55}$ Este foi o caso das terras da Fazenda da Boa Vista. Os libertos herdeiros de D. Theodora permaneceram na propriedade legada por alguns anos, sendo expulsos de lá à medida que a terra na região se tornava objeto de desejo dos condôminos mais ricos e poderosos. A divisão e a demarcação das fronteiras não fizeram cessar as disputas, que se multiplicaram ao longo dos anos, manifestando-se em conflitos criminais e em disputas judiciais.

As questões apresentadas deixam entrever as diversas formas de violência empreendidas no exercício de dominação (física e simbólica); o peso das relações pessoais e de poder; as diferentes versões de cada um dos envolvidos; o "revelado" e o "silenciado" nas argumentações judiciais, as justiças e as injustiças nas relações sociais e legais.

${ }_{55}$ Maria Helena Machado, O plano e o pânico: os movimentos sociais na década da abolição, Rio de Janeiro, Editora UFRJ, EDUSP, 1994, p. 21-66. 